\title{
The influence of the wind direction and plants on the variability of topsoil magnetic susceptibility in industrial and urban areas of southern Poland
}

\author{
Tadeusz Magiera $^{1} \cdot$ Henryk Parzentny ${ }^{1} \cdot$ Adam Lukasik $^{2}$
}

Received: 13 January 2015 / Accepted: 17 July 2015 / Published online: 25 January 2016

(c) The Author(s) 2015. This article is published with open access at Springerlink.com

\begin{abstract}
Volume magnetic susceptibility ( $\kappa$ ) was measured on the soil surface and in the vertical topsoil profile within a $300 \mathrm{~km}^{2}$ area located in an urban-industrial conurbation. The results were compared to plant species compositions in the forest storeys, elevation above sea level, and terrain geomorphology. The content and mineral composition of the magnetic fraction were determined in the soil horizons. It was found that the extent of the area with enhanced topsoil magnetic susceptibility was similar to the dominant wind direction (south-west). Enhanced $\kappa$ values were observed for the soil at the forest margin on the leeward side of the emitters as well as at sites located on exposed local elevations $(\geq 10 \mathrm{~m}$ ). There were no significant correlations between species composition of the forest stand and soil surface $\kappa$ value (measured both with and without forest litter). Soil covered with deciduous treesmostly ash (Fraxinus excelsior L.) —demonstrated higher $\kappa$ values than soil under coniferous tree species. However, our results suggest that this parameter is not controlled by individual tree species, but rather depends on distance from emission sources, intensity of magnetic particle emission, and meteorological conditions (prevailing wind directions and dynamics).
\end{abstract}

Electronic supplementary material The online version of this article (doi:10.1007/s12665-015-4846-0) contains supplementary material, which is available to authorized users.

Tadeusz Magiera

tadeusz.magiera@interia.pl

1 Department of Land Protection, University of Opole, Oleska 22, 45-052 Opole, Poland

2 Institute of Environmental Engineering, PAS, M. Skłodowskiej-Curie 34, 41-819 Zabrze, Poland
Keywords Magnetic susceptibility - Technogenic magnetic particles - Pollution distribution - Forest topsoil

\section{Introduction}

Technogenic magnetic particles (TMPs) are constantly deposited on the surface of soil located in urban areas and their vicinity. These particles usually form during the solid fuel combustion (mostly coal) or high-temperature industrial processes (iron and non-ferrous metal industries, cokeries, cement and ceramic industries, etc.). The presence of TMP in topsoil is usually associated with increased concentration of potentially toxic metals carried by those particles. The metals are bound on the extended TMP surface by adsorption forces or incorporated in crystal lattice. TMPs mainly consist of iron oxides or occur in the form of ferrite crystal structures in which the metals partially substitute iron atoms (Magiera et al. 2011a). Consequently, the presence of TMPs in topsoil (mainly in the organic horizon) is considered an indicator for heavy metal soil pollution. This fact was confirmed by many authors (Veneva et al. 2004; Klose and Makeschin 2005; Spiteri et al. 2005; Blaha et al. 2008; Jordanova et al. 2008; Lu et al. 2008; Magiera et al. 2008; Bućko et al. 2011). Soil with natural plant cover, particularly forest soil, is often used as a target for magnetic susceptibility studies because it exhibits the stratigraphic sequence of the depositing dusts in undisturbed soil horizons for a long time. At present, in situ soil magnetometry is a verified method used for identifying anthropogenic magnetic "hot spots" and their correlations with geochemical anomalies (e.g. Thompson and Oldfield 1986; Petrovský and Ellwood 1999; Evans and Heller 2003; Magiera 2004; Strzyszcz et al. 2006; Magiera et al. 2011b). 


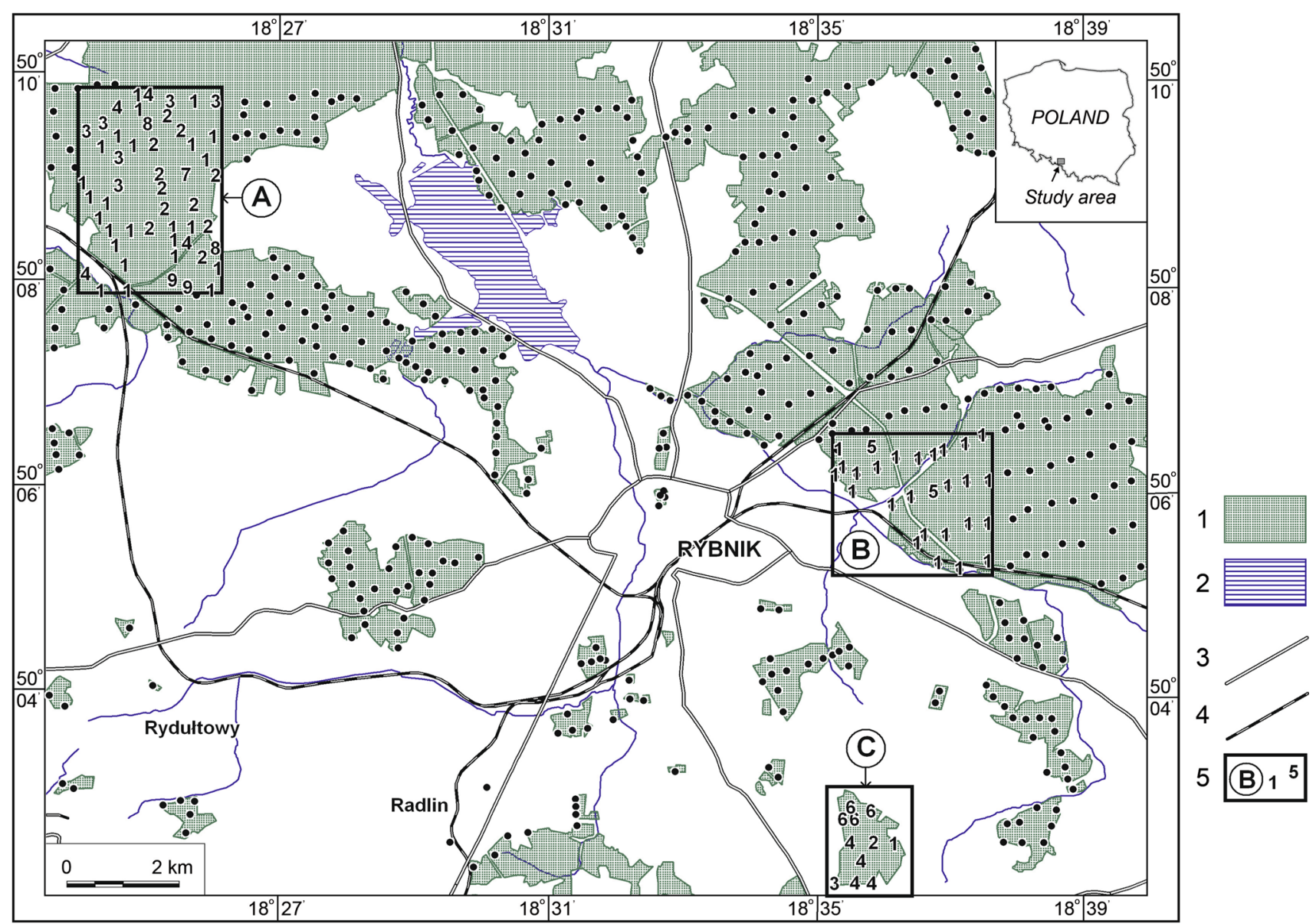

Fig. 1 Location of studied area and sampling point. 1 -forests and wooded areas, 2-Rybnik water reservoir, 3-main roads, 4-main railways, 5-selected regions $(A, B, C)$ : 1-pine, 2-beech, 3-birch, 4-oak, 5-maple, 6-ash, 7—larch, 8—spruce, 9-alder

Transportation of anthropogenic dusts in the environment proceeds in accordance with well-known mechanisms in which the wind dynamics and directions are most important (Matthias 1996). A large amount of such substances is intercepted when natural barriers (e.g. tree and bush groups, local elevations) appear in the pathway of pollutant flow. The dusts, including TMPs, deposited on leaves and needles are finally accumulated in the forest litter. The dusts are also found in the structures of tree bark and trunks, branches, leaves, needles, and roots (Kletetschka et al. 2003; Lehndorff et al. 2006; Klučiarová et al. 2008). The soil in the areas of increased (actual or historical) dust deposition exhibits high magnetic susceptibility. Nevertheless, it demonstrates high spatial variability, depending on many factors. One of them is the tree species, as different trees have various filtration properties (Strzyszcz and Magiera 1998, El-Hasan et al. 2002; Ferdyn and Strzyszcz 2003; Zawadzki et al. 2007, 2010; Łukasik et al. 2013).

The aim of this study was to determine the importance of the diverse species composition of the forest stand (in the regions with increased dust depositions) in the distribution of topsoil magnetic susceptibility $(\kappa)$ in the soil. The research was also performed in order to identify the areas in which local atmospheric conditions (wind directions) caused an increase in soil $\kappa$ value in comparison with neighbouring areas.

\section{Materials and methods}

\section{Environmental site description}

The study area (coordinates: $18^{\circ} 23^{\prime} 19^{\prime \prime} \mathrm{E}-18^{\circ} 40^{\prime} 08^{\prime \prime} \mathrm{E}$ and $50^{\circ} 10^{\prime} 21^{\prime \prime} \mathrm{N}-50^{\circ} 02^{\prime} 01^{\prime \prime} \mathrm{N}$; in total: $303.8 \mathrm{~km}^{2}$ ) was located in the Rybnik Plateau in the south-western part of Upper Silesia (Figure 1) in zone of mild temperate continental climate with average annual temperature $+8{ }^{\circ} \mathrm{C}\left(+18{ }^{\circ} \mathrm{C}\right.$ in July and $-2{ }^{\circ} \mathrm{C}$ in January) and precipitation between 600 and $900 \mathrm{~mm}$ (SAM 2014).

The large 1775 MW power plant opened in 1972 and concentration of many other industrial sources (their 


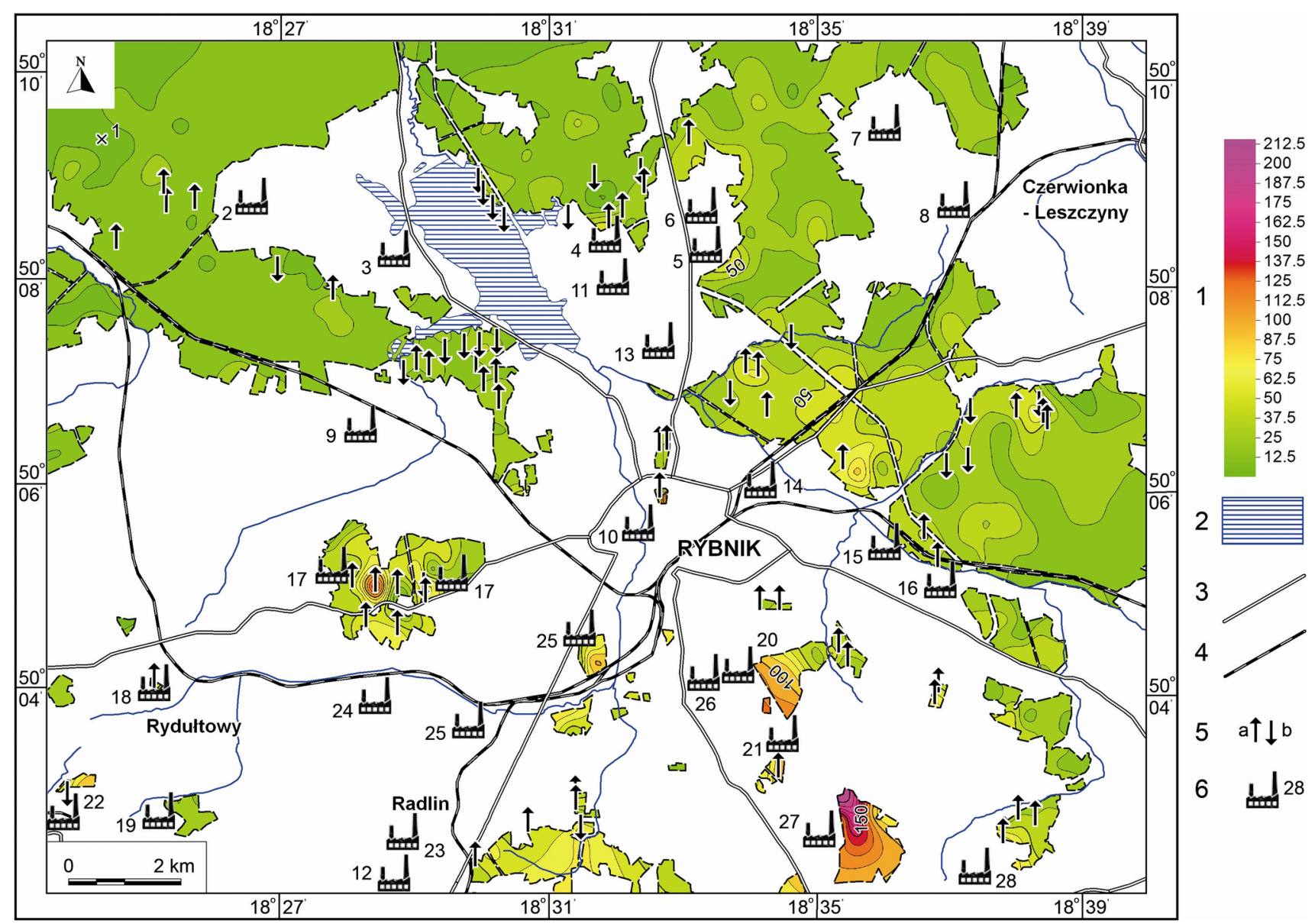

Fig. 2 Map of magnetic susceptibility $(\kappa)$ measured directly on the soil surface. (1) Colour scale of $\kappa\left(\times 10^{-5}\right.$ SI units), (2) Rybnik water reservoir, (3) main roads, (4) main railways, (5) measure points: (a) located $\geq 10 \mathrm{~m}$ AGL $(b) \leq 10 \mathrm{~m}$ AGL, (6) location of background point (1) and main emission sources: 2-10 urban and traffic sources (2-Rybnik Grabownia, 3-Rybnik Górka, 4-Rybnik Golejów, 5Książenice, 6-Rybnik Lasoki, 7-Rybnik Centrum, 8-Rybnik Chwałęcice, 9-Lyski Zwonowice, 10-Jejkowice), 11-Rybnik

location is presented in Figs. 2 and 3) as well as thousands of households using coal for heating caused that the annual total dust emission in the end of 1980s was in Rybnik $35 \mathrm{~g} \mathrm{~m}^{-2}$ and in 1999 it was even $45 \mathrm{~g} \mathrm{~m}^{-2}$. After closing some old plants and modernization of others including application of high efficient precipitators, the annual dust emission was reduced to the amount of $3.2 \mathrm{~g} \mathrm{~m}^{-2}$ in 2013 (Magiera et al. 2015).

Brunic Arenosols dominated over Luvisols and Cambisols in the study area. Dystrict Cambisols, Endoeutric Cambisols, Luvisols, and Fluvi Gleysols occurred mainly in the southern and south-western part of the study area, whereas Haplic Podzols and Haplic Arenosols were observed in its northern part. Haplic Fluvisols were found in the Ruda River valley and, sporadically, in the Rybnik Reservoir surroundings. The soils were formed on the Pleistocene gravels and sands (Pietrzykowski et al. 2010).
Power Plant, 12-Radlin Coke Plant, 13-16 old and closed steel plants (13-Rybnicka Kuźnia, 14-Silesia, 15-Ligocka Kuźnia, 16- Huta Gotartowska), 17-21 mining wastes storage facilities (17Beatensglück, 18-Karol, 19-Anna, 20-Chwałowice, 21Jankowice), 22-28 coal mines and electrical power and heating plant CHP (22-Anna, 23-Marcel, 24-Rymer, 25-Hyom, 26Chwałowice, 27-Jankowice, 28-Żory)

The most commonly observed tree species was pine (Pinus sylvestris L.), with admixtures of beech (Fagus sylvatica L.) and birch (Betula pendula Roth). Deterioration of tree-stand quality was found on the forest margins, where increased soil $\kappa$ value was observed. Some of the pines and birches growing on the windward side had damaged assimilation apparatuses and thinned tree crowns. The process of tree weakening in the Rybnik Agglomeration vicinity under the influence of pollutant emission was described in detail by Harabin et al. (1980). The following tree species were very seldom found in the study area, listed in descending order: oak (mainly Quercus robur L.), maple (Acer platanoides L.), alder (Alnus glutinosa L.), larch (Larix decidua Mill. ssp. decidua), ash (Fraxinus excelsior L.), poplar (Populus tremula L.), and spruce (Picea abies,(L.) Karsten). Birch (Betula pendula Roth) was the dominant species in woodlands and coppices. The 


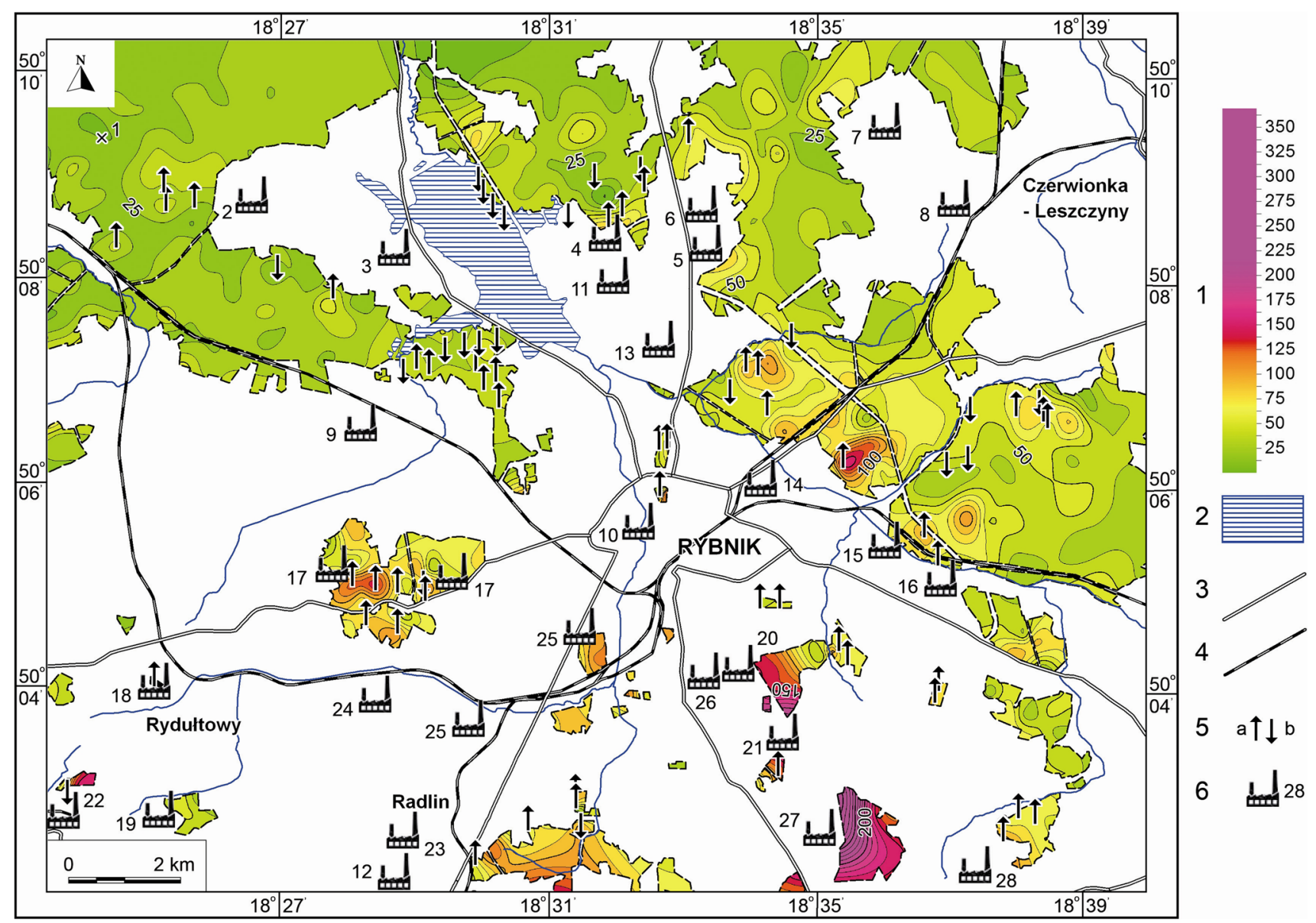

Fig. 3 Map of magnetic susceptibility ( $\kappa$ ) measured after Oi subhorizon removal. Refer to Fig. 2 caption for more details

understorey was mainly formed by pine (Pinus sylvestris L.) and birch (Betula pendula Roth) undergrowth. Often, there was neither understorey nor groundcover in the lower forest storeys. Various grass species dominated over bilberry (Vaccinium myrtillus L.) in the groundcover. Ferns (Pteridium aquilinum (L.) Kuhn) and mosses (Polytrichum commune Hedw.) were less often. The forest litter was mainly composed of leaves and (to a lesser extent) needle cover, pine-cones, and small sticks. As routine works related to the forest growing, protection, and organization were performed, there were sites without forest litter or humus, and also ploughed soil spots.

\section{Methods of study}

The topsoils (up to $25 \mathrm{~cm}$ depth) found in the forests and wooded areas were examined. The researchers created a grid of 515 measurement points (average distance between points: $350 \mathrm{~m}$ ), at which the volume magnetic susceptibility ( $\kappa$ ) was measured on the soil surface. The $\kappa$ measurements were taken with a Bartington MS2D sensor (with detection limit $0.1 \times 10^{-5} \mathrm{SI}$ units) according to the procedure described by Schibler et al. (2002). The magnetic susceptibility measurements were correlated with the GPS geographic coordinates. Two $\kappa$ measurement series of every point were performed, i.e. with and without forest litter (after the Oi subhorizon removal). Each measurement result was the arithmetic mean obtained from 10 to 20 individual $\kappa$ value measurements taken within a circle (radius approximately $1.0 \mathrm{~m}$ ).

The average magnetic susceptibility $\kappa$ and the content of the magnetic fraction in it were calculated with the arithmetic mean. The main descriptive statistics of the measured quantities are given in Table 1 . The mean soil $\kappa$ value was calculated in different sections of AMSL (above mean sea level) and AGL (above ground level) altitudes (Table 2). Isolines of the $\kappa$ values with and without forest litter (Figs. 2 and 3, respectively) were prepared for the forests and wooded areas. The main wind directions and its average speed (Fig. 4) in the study area were defined with the available air quality measurement results (SAM 2014).

The dominant type of vegetation and individual tree species in the defined plant groups (representing particular forest storeys) were identified for each measurement point 
Table 1 Basic statistic parameters of magnetic susceptibility measured directly on the soil surface (with litter) and after the litter removal (without litter)

\begin{tabular}{llll}
\hline Statistics/area & \multicolumn{2}{l}{$\begin{array}{l}\text { Magnetic susceptibility }(\kappa) \\
\left(\times 10^{-5} \mathrm{SI}\right)\end{array}$} & \begin{tabular}{l} 
Magnetic \\
fraction without \\
\cline { 2 - 3 }
\end{tabular} \\
\cline { 2 - 3 } With litter & $\begin{array}{l}\text { Without } \\
\text { litter }\end{array}$ & \\
\hline Study area & & & \\
Number of sites (n) & 515 & 515 & 43 \\
Average & 32.5 & 51.2 & 4 \\
Median & 26.1 & 42.4 & 2.8 \\
Range & $5.8-192.1$ & $12.0-315.0$ & $0.3-26.2$ \\
Standard deviation & 21.6 & 33.8 & 4.5 \\
Coeff. of skewness & 2.8 & 3.4 & 3.7 \\
Correlations & & & \\
Pearson & {$[1: 3]=0.21$} & {$[1: 2]=0.89$} & {$[2: 3]=0.62$} \\
& $p=0.175$ & & \\
Spearman & {$[1: 2]=0.99$} & {$[1: 3]=0.99$} & {$[2: 3]=1.00$} \\
\hline
\end{tabular}

Table 2 Average soil magnetic susceptibility $(\kappa)$ in relation to the altitude

\begin{tabular}{lrll}
\hline Altitude & $N$ & \multicolumn{2}{l}{ Magnetic susceptibility $\kappa\left(\times 10^{-5} \mathrm{SI}\right)$} \\
\cline { 3 - 4 } & \multicolumn{2}{l}{ With litter } & Without litter \\
\hline Absolute altitude & (m.a.s.1.) & \\
$>290$ & 4 & 54.6 & 88.3 \\
$270-290$ & 78 & 45.9 & 69.6 \\
$250-270$ & 170 & 32.5 & 52.5 \\
$230-250$ & 182 & 31.1 & 48.1 \\
$210-230$ & 81 & 22.3 & 36.1 \\
Relative (m) & & & 73.1 \\
$>10$ & 51 & 46.0 & 49.2 \\
Normal & 449 & 31.2 & 36.7 \\
$<10$ & 15 & 25.8 & \\
Correlations between & magnetic susceptibility & and & altitude \\
Absolute altitude & & & $0.83^{*}$ \\
Pearson & 515 & $0.86^{*}$ & $0.99^{*}$ \\
Spearman & 515 & $0.99 *$ & \\
\hline
\end{tabular}

$* p<0.05$

of magnetic susceptibility. The mean $\kappa$ value of the soil was calculated for the sites in which the plant groups occurred. Additionally, the correlation between the presence of these plant groups and soil $\kappa$ value was examined using the Spearman's rank correlation coefficient (Table 3).

In the study area, there were 43 places in which the soil surface magnetic anomalies were observed. At those sites, 25-cm-deep soil cores were collected with the Humax soil probe. The magnetic susceptibility $(\kappa)$ of each soil core was measured along its whole length (resolution $1 \mathrm{~cm}$ ) with the Bartington MS2C sensor (with detection limit $0.1 \times 10^{-5}$ SI units). The genetic horizons of the soil (Fig. 5) were characterized according to the WRB soil classification (IUSS 2007). The grain-size analysis was performed following the FAO procedure (Guidelines for soil description 2006). Samples taken from individual soil horizons and subhorizons of Humax cores were air-dried at room temperature and shaken through a set of sieves that have progressively smaller openings in a range of $2.0-0.05 \mathrm{~mm}$. Material from each soil horizons and subhorizons in the cores was separated into magnetic (Mf) and non-magnetic fractions, and their weight percentages were determined. The separation was performed by using hand magnet. The mineral composition of the magnetic fraction was determined with X-ray analysis and reflected light microscopy. The results of the soil core examinations helped to characterize the pollution level of the soil with TMPs in the study area profile (Fig. 5).

Pearson's Chi-squared test, the Kolmogorov-Smirnov test, and the Shapiro-Wilk test (statistical significance level $p=0.05$ ) were applied to assess the correctness of the average value calculation. The Pearson correlation coefficients and Spearman's rank correlation coefficients were used to identify correlations between all measured variables (Tables 1 and 2). Additionally, the statistical significance level $p$ was calculated for the $t$ test of the investigated variables; $p$ values above are shown in Tables 1 and 2 .

\section{Results and discussion}

\section{Soil and forest floor characteristics}

On the base of morphological analysis of topsoil cores, the following information about the composition and development of organic horizon and uppermost part of soil profiles was obtained. In the study area, the organic horizon was $2.2 \mathrm{~cm}$ thick (Fig. 5). It consisted of:

- The Oi1 subhorizon with average thickness of $0.2 \mathrm{~cm}$, composed from unchanged large parts of leaves and needle cover (observed on $93 \%$ of the study area);

- The $\mathrm{Oi}_{2}$ subhorizon with average thickness of $1.2 \mathrm{~cm}$, containing pieces of primary forest litter, crushed like pipe tobacco (observed on $83 \%$ of the study area);

- The fermentative Oe subhorizon with average thickness of $0.7 \mathrm{~cm}$, composed mainly from fibrous and loosely crumbled rotten forest litter (observed on $79 \%$ of the study area); 


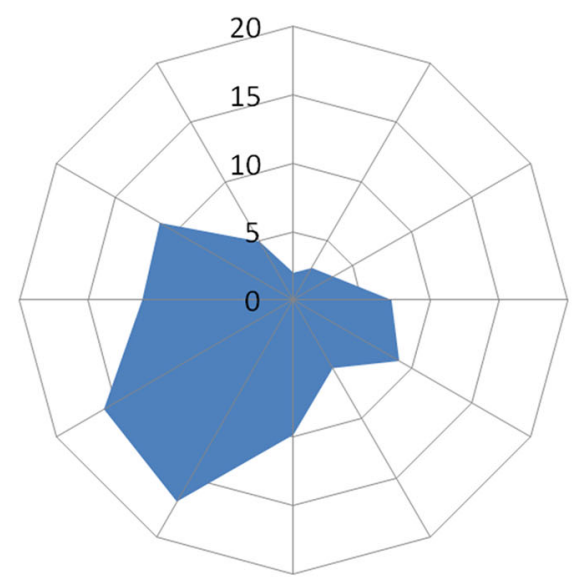

A

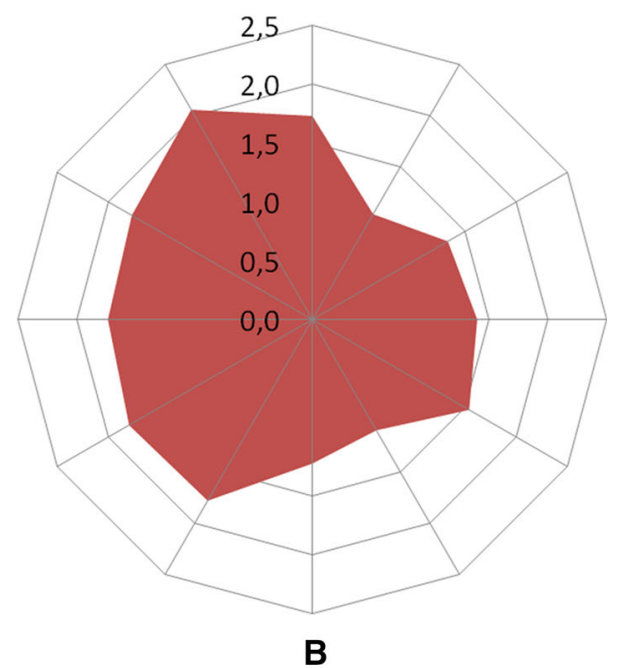

Fig. 4 Main wind directions (a) and wind speed (b) based on data from 2010 to 2013 in the area of study (SAM 2014)

- The humic Oa subhorizon with average thickness $1.1 \mathrm{~cm}$, composed from highly decomposed and formless organic substances (observed on $79 \%$ of the study area).

The border between $\mathrm{O}$ and $\mathrm{Ah}$ horizon was not sharp. In many cases the intermediate OaAh horizon (and less often the mixed $\mathrm{Oa} / \mathrm{Ah}$ subhorizon) was observed. The morphology of the whole organic horizon indicated the presence of fresh and wet mor humus, and (less often) fresh moder in the study area.

The Ah horizon was found in $98 \%$ of topsoils and its mean thickness was $3.8 \mathrm{~cm}$ (Fig. 5). It mainly consisted of loose medium- and coarse-grained sand (slightly gravelled) and gravel with large admixtures of black humic substance. It overlay the eluvial $\mathrm{E}$ horizon through the intermediate AhE horizon. The E horizon was found in $23 \%$ of measurement points, only where Podzols and Albic Cambisols were found. The average thickness of the $\mathrm{E}$ horizon was
$2.4 \mathrm{~cm}$, and it was mainly composed of medium-grained sand and gravel. The E horizon contacted the illuvial B horizon through the visible colour change and a thin intermediate layer $(0.5-1.5 \mathrm{~cm})$. The B horizon was seen in $79 \%$ of the soil profiles. Its mean thickness was $6.4 \mathrm{~cm}$. It normally contained medium-grained sand and, to a lesser extent, gravels. The admixtures of iron compounds and, sometimes, loams cementing the skeletal grains were often found in this horizon. The bedrock $\mathrm{C}$ horizon was found in $9 \%$ of the studied soil cores and was normally built from highly gravelled sand and gravels. The bedrock R horizon was not found in the very few pits and natural outcrops (up to the $1.3 \mathrm{~m} \mathrm{depth}$ ).

Most studied sites are of urban areas in which small patches of mixed-tree forest, woodlands, and coppices were found (Fig. 1). The coniferous forest stand dominated over the deciduous one in most of the study areas. Forest parts co-occurred with fairly diverse forest stands, particularly in the relatively large and small areas (regions $\mathrm{A}$ and $\mathrm{C}$, respectively). Pine monoculture was observed in the $\mathrm{B}$ region (Fig. 1).

\section{Magnetic susceptibility of soils}

In the study area, the soil magnetic susceptibility $(\kappa)$ was lower (measurement with forest litter) or comparable and lower (measurement without forest litter) than the soil $\kappa$ values observed in other Polish and European industrial regions (Boyko et al. 2004; Schmidt et al. 2005; Fialová et al. 2006; Magiera et al. 2006a; Magiera and Zawadzki 2007; Wojas 2009). In the southern and central part of the study area, there were a few magnetic anomalies observed (i.e. regions in which the $\kappa$ value was greater than $50 \times 10^{-5}$ SI units-measured on the surface; Fig. 2). Following Strzyszcz et al. (2006), if the $\kappa$ value is above $50 \times 10^{-5}$ SI units, the soil was considered severely threatened with the heavy metal pollution (heavy metals co-occurring with TMPs). The course (shape) of isoline $50 \times 10^{-5}$ SI units and the range of the observed anomalies probably reflected the size of the dust pollutant clouds from the present and historical emitters (Fig. 2). In the case of measurements of magnetic susceptibility after the litter removal isoline $75 \times 10^{-5}$ SI would be the better indicator (Fig. 3). The anomaly extent roughly followed the main wind direction (SW) observed in the study area in the past (Harabin et al. 1980) and at present (Fig. 4). Both in the study area and in all of Upper Silesia, the highest air pollutant concentrations are observed when anti-cyclonic circulation with dominant air advection from the S and SW directions occurs. Such concentrations are also measured when there is no air advection or there is air stagnation in the high-pressure area centre (Leśniok et al. 2010). A large number of windless days $(25.9 \%)$ and low average annual 
Table 3 Average soil magnetic susceptibility $(\kappa)$ in relation to vegetation cover

\begin{tabular}{|c|c|c|c|c|c|}
\hline \multirow[t]{2}{*}{ Group of plants } & \multicolumn{2}{|c|}{ Magnetic susceptibility $\left(\times 10^{-5} \mathrm{SI}\right)$} & \multirow{2}{*}{$\begin{array}{l}\text { Frequency } \\
\%\end{array}$} & \multicolumn{2}{|c|}{ Spearman correlation } \\
\hline & 1 & 2 & & 1 & 2 \\
\hline Deciduous forest & 40.1 & 62.4 & 38.8 & $0.23 *$ & $0.23 *$ \\
\hline Coniferous forest & 27.6 & 43.9 & 61.2 & $-0.23 *$ & $-0.23 *$ \\
\hline Pine & 27.7 & 44.0 & 59.2 & $-0.22 *$ & $-0.23 *$ \\
\hline Beech & 41.8 & 64.2 & 18.6 & $0.21 *$ & $0.21 *$ \\
\hline Birch & 35.6 & 55.4 & 8.5 & $0.03 * *$ & $0.03 * *$ \\
\hline Oak & 33.1 & 51.3 & 4.1 & $0.03 * *$ & $0.03 * *$ \\
\hline Maple & 35.2 & 54.3 & 3.5 & $0.04 * *$ & $0.04 * *$ \\
\hline Ash & 124.5 & 204.6 & 1.2 & $0.16^{*}$ & $0.16^{*}$ \\
\hline Larch & 27.5 & 44.0 & 1.4 & $0.00 * *$ & $0.00 * *$ \\
\hline Alder & 24.6 & 38.8 & 2.1 & $-0.06^{* *}$ & $-0.06 * *$ \\
\hline Poplar & 38.9 & 61.4 & 0.6 & $-0.05 * *$ & $-0.05 * *$ \\
\hline Shrubs & 29.7 & 46.9 & 19.8 & $-0.06^{* *}$ & $-0.06^{* *}$ \\
\hline Brushwood trees & 36.1 & 56.9 & 25.6 & $0.06 * *$ & $0.06 * *$ \\
\hline Without understory & 32.2 & 50.4 & 55.5 & $0.02 * *$ & $0.02 * *$ \\
\hline Fern & 22.9 & 36.4 & 4.5 & $-0.12 *$ & $-0.12 *$ \\
\hline Grass & 29.2 & 46.7 & 41.0 & $-0.11^{*}$ & $-0.11 *$ \\
\hline Moss & 33.0 & 51.5 & 1.4 & $0.01 * *$ & $0.01 * *$ \\
\hline Blueberry & 24.9 & 39.6 & 14.8 & $-0.16^{*}$ & $-0.16^{*}$ \\
\hline Without undergrowth & 39.6 & 62.0 & 38.3 & $0.28 * *$ & $0.28 * *$ \\
\hline Leaves & 33.8 & 53.1 & 72.0 & $0.06 * *$ & $0.06 * *$ \\
\hline Needles & 26.5 & 41.9 & 22.3 & $-0.16^{*}$ & $-0.16^{*}$ \\
\hline Without litter & & 65.8 & 5.2 & $0.16^{*}$ & $0.16^{*}$ \\
\hline Furrow soil & 31.7 & 49.6 & 6.6 & $0.01 * *$ & $0.01 * * * *$ \\
\hline Marsh & 36.7 & 57.2 & 2.9 & $0.05 * *$ & $0.05 * *$ \\
\hline
\end{tabular}

$* p<0.05 ; * * p>0.05$ wind speed (e.g. $1.0-2.0 \mathrm{~m} / \mathrm{s}$ and $1.7-3.5 \mathrm{~m} / \mathrm{s}$ for past and present, respectively) cause dust deposition in the study area (Fig. 4). Furthermore, dust pollutant accumulation was also facilitated by the local land morphology: poorly ventilated basin and valleys predominate over the flat and upland forms. The accumulation was also aided by the fact that the temperatures observed in the upland regions were higher during the day and lower at night than the temperatures measured for the lower areas.

At some research points, the soil with increased magnetic susceptibility was found in the land adjoining the forest margin (Figs. 2 and 3). The size of these land parts was defined by the $\kappa$ value isolines in the vicinity of some emitters (e.g. emitters 5, 6, 14-16, 20, 26-28; Figs. 2 and 3 ). Their shapes were similar to the shapes of forest areas or wind direction. This finding indicates an important role of the forest as a semi-permeable curtain for the dust and gaseous pollutant stream transported by wind from the emitters.

It was observed that soil magnetic susceptibility increased with the elevation of the ground surface above sea level (Table 2). Surface areas elevated higher than
$10 \mathrm{~m}$ (AGL) demonstrated higher $\kappa$ values than neighbouring areas (Figs. 2 and 3; Table 2). On the other hand, the $\kappa$ values observed for the land located below the $10 \mathrm{~m}$ level were lower than in the neighbouring areas. The discussed correlations are in agreement with the alreadymentioned important role of wind direction played in dust pollutant deposition and selective enrichment of topsoils with magnetic particles.

In the topsoils, a visible $\kappa$ maximum was observed in the lower part of the organic horizon (OaAh) (Fig. 5). It was caused by the magnetic fraction present in the soil, which was confirmed by the statistically relevant correlation coefficient values (Table 1). It was also proven by the similar course of the changes in soil $\kappa$ values and the magnetic fraction content in the soil profile (Fig. 5). The magnetic fraction was composed of magnetite ferrospheres, cenospheres of not fully burnt organic matter and, to a lesser extent, isometric particles of hematite and maghemite, particles of the pyrite/goethite pseudomorph, and even small particles of metallic iron $(\alpha \mathrm{Fe})$ (Fig. 6). Concentrations of such particles are generally considered indicators of technogenic pollutants brought about by fossil 
Fig. 5 Average distribution of magnetic susceptibility (Ms) and magnetic fraction content (Mf) in soil profile, including information concerning the grain-size fractions $(C B-$ cobbles, $C O S$ - coarse sand, $G$-gravel, $G S$-gravel, and sand, $M S$-medium sand) and contents of magnetic minerals in Mf ( $\alpha$-magnetite ferrospheres $\gg$ isometric particles of hematite $=$ and maghemite $\gg$ pyrite/goethite pseudomorphs and metallic iron, $\beta$-isometric particles of magnetite $>$ hematite, $\gamma-$ isometric particles hematite $>$ magnetite
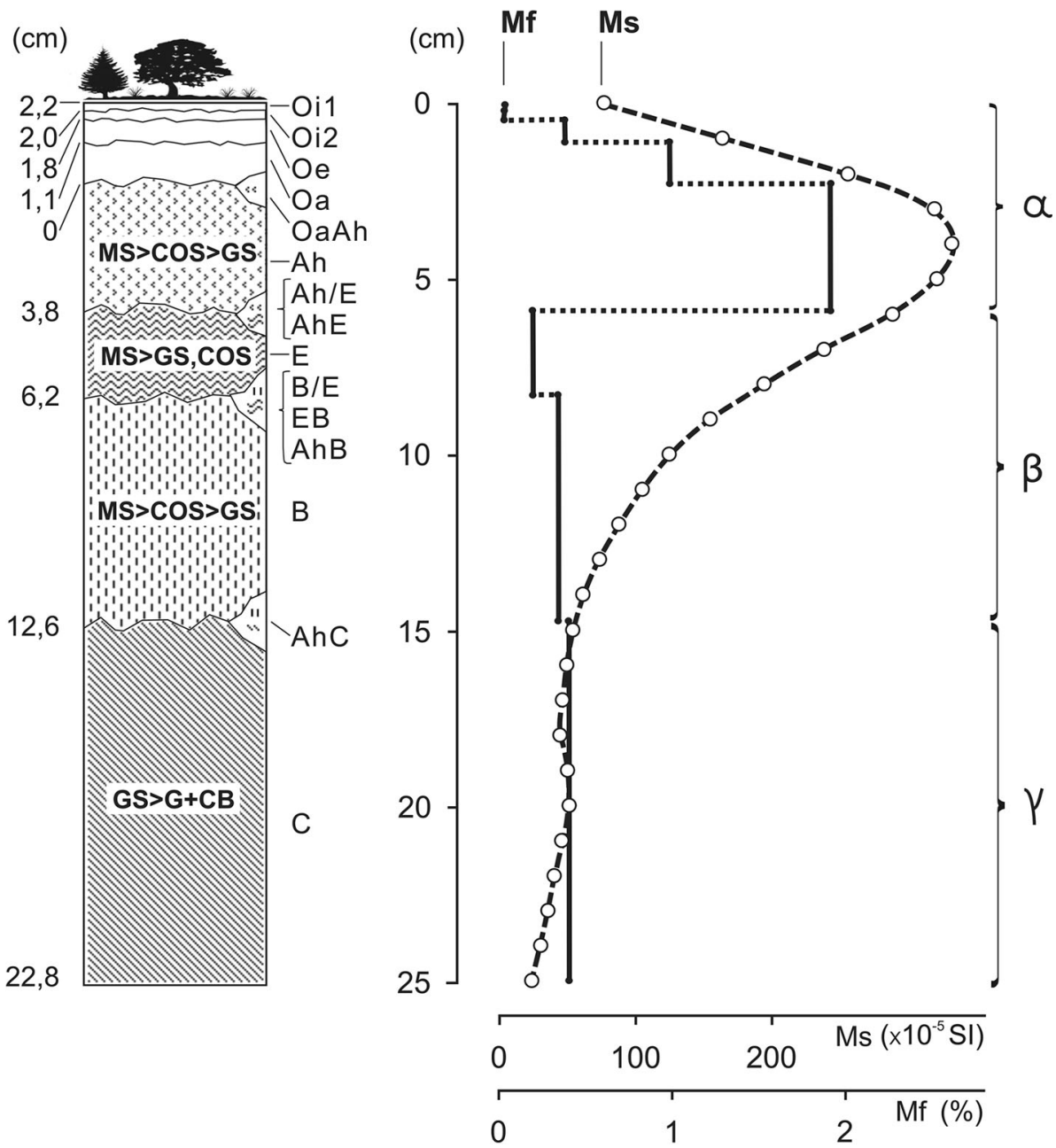

wind direction and dynamics (Fig. 4). The ash grew only in one area (region C; Fig. 1), co-occurring with pine (Pinus sylvestris L.) and birch (Betula pendula Roth). Large numbers of pines and birches were also found in another research region (region A; Fig. 1), but they did not affect the increase in the soil magnetic susceptibility. In the same region, the tree species was highly varied, but this did not significantly influence the topsoil $\kappa$ value. On the other hand, soil magnetic susceptibility was not uniform (Fig. 2 and 3 ) in the region where only pines grew (region B; Fig. 1). Apart from the ash-growing site, a relatively high topsoil $\kappa$ value was observed in the areas where beech (Fagus sylvatica L.) and poplar (Populus tremula L.) occurred (Table 3). The lowest soil magnetic susceptibility was measured at the sites where spruce (Picea abies (L.) H. Karst) and alder (Alnus glutinosa L.) were found.

The plant groups making up the understorey did not significantly influence the magnetic susceptibility of the topsoil on which the plants grew (Table 3). The topsoil $\kappa$ value at the places without groundcover or forest litter was higher than at the sites in which they were found. Low soil magnetic susceptibility was observed at the spots in which 

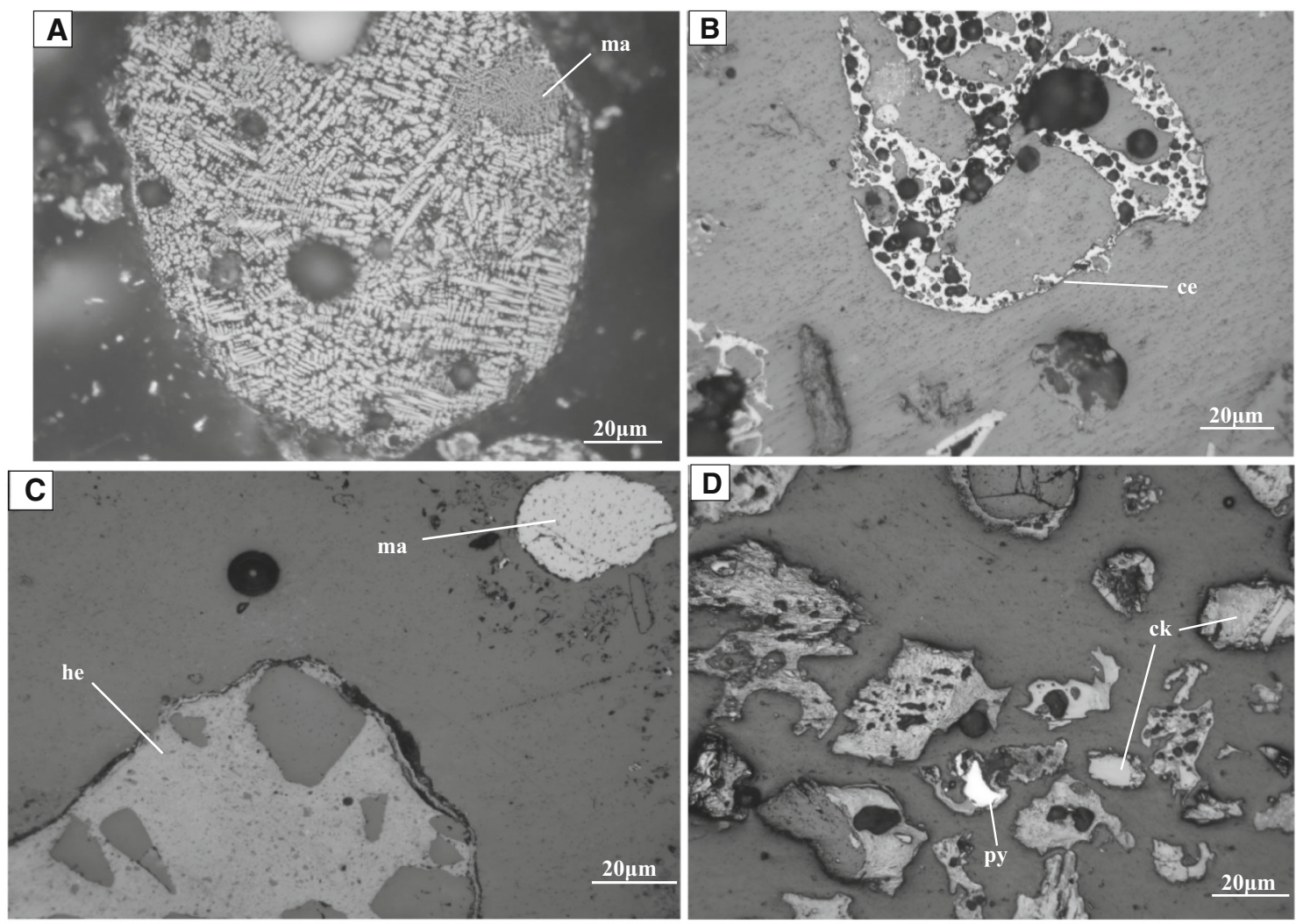

Fig. 6 Magnetic fraction from soil horizon. a-Ferrosphere with dendritic magnetite crystallites $(m a)$ in Ah horizon, b-cenosphere ( $(c e)$ in Oe subhorizon, c-isometric magnetite $(m a)$ and hematite $(h e)$ in b horizon, d-pyrite ( $p y)$ with coke ( $c k$ ) grain in Oi subhorizon

needle cover was found in the forest litter and at which ferns grew (Pteridium aquilinum (L.) Kuhn). The higher $\kappa$ value of the soil covered with deciduous forest litter resulted from two factors. Firstly, dusts were more often emitted in the direction of the forest dominated by deciduous species. Secondly, deciduous trees are more efficient in intercepting dust particles from the pollutant stream than coniferous trees. Magnetic particles are found in the leaf and needle structures of various tree species (Schädlich et al. 1995; Matzka and Maher 1999; Hanesch et al. 2003; Urbat et al. 2004; Gautam et al. 2005; Lehndorff et al. 2006; Maher et al. 2008; Sagnotti et al. 2009). However, these are few inclusions of single particles without any significant influence on soil magnetic susceptibility.

\section{Conclusions}

In the Rybnik Agglomeration, the following soil magnetic susceptibility $(\kappa)$ anomalies were observed:

- The extent of the area defined by the isolines with high soil $\kappa$ values overlapped with the dominant wind directions (SW);
- The enhanced topsoil $\kappa$ value was found on the forest margins on the leeward side of the pollutant emitters;

- The topsoil $\kappa$ value was higher at the sites located at relatively higher elevations.

In the soil organic horizon, there was a large content of particles of magnetite $\gg$ hematite $=$ maghemite $\gg$ pyrite/goethite pseudomorphs and metallic iron, which might attribute to the technogenic enhancement in topsoil magnetic susceptibility $\kappa$ in the study area.

There was insignificant correlation or no correlation between the species composition of the forest storeys and the soil magnetic susceptibility $\kappa$ measured with and without forest litter. The soil covered with deciduous trees (particularly ash) had higher magnetic susceptibility than the topsoil on which coniferous trees grew. Nonetheless, the correlation did not depend on the filtration properties of trees. It resulted from the fact that most of the local pollution sources were surrounded by deciduous forest complexes.

Acknowledgments We would like to thank the professional Proofreading services.com for the English text correction. We also thank two anonymous reviewers for their constructive comments and suggestions that improved the manuscript. 
Open Access This article is distributed under the terms of the Creative Commons Attribution 4.0 International License (http://crea tivecommons.org/licenses/by/4.0/), which permits unrestricted use, distribution, and reproduction in any medium, provided you give appropriate credit to the original author(s) and the source, provide a link to the Creative Commons license, and indicate if changes were made.

\section{References}

Blaha U, Sapkota B, Appel E, Stanjek H, Rösler W (2008) Microscale grain-size analysis and magnetic properties of coal-fired power plant fly ash and its relevance for environmental magnetic pollution studies. Atmos Environ 42:8359-8370

Boyko T, Scholger R, Stanjek H, Team MAGPROX (2004) Topsoil magnetic susceptibility map ping as a tool for pollution monitoring: repeatability of in situ measurements. J Appl Geophys 55:249-259

Bućko MS, Magiera T, Johanson B, Petrovský E, Pesonen LJ (2011) Identification of magnetic particulates in road dust accumulated on roadside snow using magnetic, geochemical and micromorphological analyses. Environ Pollut 159:1266-1276

El-Hasan T, Al-Omari H, Jiries A, Al-Nasir F (2002) Cypress Tree (Cupressus Semervirens L.) bark as an indicator for heavy metal pollution in the atmosphere of Amman City, Jordan. Environ Int 28:513-519

Evans ME, Heller F (2003) Environmental Magnetism. Academic Press-Elsevier, Amsterdam

Ferdyn M, Strzyszcz Z (2003) Magnetic susceptibility and heavy metal contents of forest soils under variable dominant tree species in Pruhonice Park. Arch Environ Prot 29:71-76

Fialová H, Maier G, Petrovský E, Kapička A, Boyko T, Scholger R, Team MAGPROX (2006) Magnetic properties of soils from sites with different geological and environmental settings. J Appl Geophys 59:273-283

Gautam P, Blaha U, Appel E (2005) Magnetic susceptibility of dustloaded leaves as a proxy of traffic-related heavy metal pollution in Kathmandu city, Nepal. Atmos Environ 39:2201-2211

Guidelines for soil description (2006), FAO, Rome, pp 1-110

Hanesch M, Scholger R, Rey D (2003) Mapping dust distribution around an industrial site by measuring magnetic parameters of tree leaves. Atmos Environ 37:5125-5133

Harabin Z, Kawalec A, Warteresiewicz M, Węgierek S, Wrona A (1980) The effect of industrial emission on Pinus Silvestris L. in chosen forests groups in Rybnik Forest Inspectorate. Arch Environ Prot 1:107-139 (in Polish)

IUSS Working Group WRB (2007) World reference base for soil resources 2006, first update 2007. World Soil Resources Reports No. 103. FAO, Rome

Kapička A, Petrovský E, Jordanova N, Podrazský V (2001) Magnetic parameters of forest top soils in Krkonose Mountains, Czech Republic. Phys Chem Earth (A) 26:917-922

Kletetschka G, Žila V, Wasilewski PJ (2003) Magnetic anomalies on the tree trunks. Stud Geophys Geod 47:371-379

Klose S, Makeschin F (2005) Soil properties in coniferous forest stands along a fly-ash deposition gradient in Eastern Germany. Pedosphere 15:681-694

Klučiarová D, Márton P, Pichler V, Márton E, Túnyi I (2008) Pollution detection by magnetic susceptibility measurements aided by the stemflow effect. Water Air Soil Pollut 189:213-223

Lehndorff E, Urbat M, Schwark L (2006) Accumulation histories of magnetic particles on pine needles as function of air quality. Atmos Environ 40:7082-7096
Leśniok M, Małarzewski Ł, Niedźwiedź T (2010) Classification of circulation types for southern Poland with an application to air pollution concentration in Upper Silesia. Phys Chem Earth 35:516-522

Lu SG, Bai SQ, Fu LX (2008) Magnetic properties as indicators of Cu and $\mathrm{Zn}$ contamination in soils. Pedosphere 18:479-485

Łukasik A, Rachwał M, Strzyszcz Z (2013) Application of magnetic susceptibility of soils for identification of potential sources of secondary dust emission in urban parks. Soil Sci Annu 63:34-40

Magiera T (2004) Wykorzystanie magnetometrii do oceny zanieczyszczenia gleb i osadów jeziornych. Works \& Studies 59 (Ed. Rosik-Dulewska), Inst. Environ. Eng. Polish Academy Sciences, Zabrze

Magiera T, Zawadzki J (2007) Using of high-resolution topsoil magnetic screening for assessment of dust deposition: comparison of forest and arable soil datasets. Environ Monit Assess $125: 19-28$

Magiera T, Strzyszcz Z, Kapička A, Petrovský E, Team MAGPROX (2006a) Discrimination of lithogenic and anthropogenic influences on topsoil magnetic susceptibility in Central Europe. Geoderma 130:299-311

Magiera T, Strzyszcz Z, Rachwał M (2006b) Magnetic susceptibility of forest topsoils in mountains regions of southern Poland based on field measurement techniques. Pol J Soil Sci 39:101-108

Magiera T, Strzyszcz Z, Rachwał M (2007) Mapping particulate pollution loads using soil magnetometry in urban forests in the Upper Silesia Industrial Region, Poland. For Ecol Manag 248:36-42

Magiera T, Kapićka A, Petrovský E, Strzyszcz Z, Fialová H, Rachwał M (2008) Magnetic anomalies of forest soils Upper SilesiaNorthern Moravia region. Environ Pollut 156:618-627

Magiera T, Jabłońska M, Strzyszcz Z, Rachwał M (2011a) Morphological and mineralogical forms of technogenic magnetic particles in industrial dusts. Atmos Environ 45:4281-4290

Magiera T, Jankowski M, Świtoniak M, Rachwał M (2011b) Study of forest soils on an area of magnetic and geochemical anomaly in North-eastern Poland. Geoderma 160:559-568

Magiera T, Parzentny H, Róg L, Chybiorz R, Wawer M (2015) Spatial variation of soil magnetic susceptibility in relation to different emission sources in southern Poland. Geoderma 255-256:94-103

Maher BA, Moore C, Matzka J (2008) Spatial variation in vehiclederived metal pollution identified by magnetic and elemental analysis of roadside tree leaves. Atmos Environ 42:364-373

Matthias AD (1996) Atmospheric pollution. In: Pepper ID, Gerba CP, Brusseau ML (eds) Pollution science. Academic Press Inc., London, pp 171-186

Matzka J, Maher BA (1999) Magnetic biomonitoring of roadside tree leaves: identification of spatial and temporal variations in vehicle-derived particulates. Atmos Environ 33:4565-4569

Petrovský E, Ellwood BB (1999) Magnetic monitoring of air-, land-, and water pollution. In: Maher BA, Thompson R (eds) Quaternary climates, environments and magnetism. Cambridge University Press, Cambridge, pp 279-322

Pietrzykowski M, Krzaklewski W, Tomanek M, Hajduk P (2010) Areal balance management, tree stands and sites characteristic on a reclaimed spoil heap of hard coal mining in the Rybnik Forest Inspectorate (Upper Silesian Industrial Region-GOP). Inżynieria Środowiska 17, Zeszyty Naukowe Nr 137:75-85 (in Polish)

Rothwell JJ, Lindsay JB (2007) Mapping contemporary magnetic mineral concentrations in peat soils using fine-resolution digital terrain data. Catena 70:465-474

Sagnotti L, Taddeucci J, Winkler A, Cavallo A (2009) Compositional, morphological, and hysteresis characterization of magnetic 
airborne particulate matter in Rome, Italy. Geochem Geophys Geosyst 10:1-17

SAM Silesian Air Monitoring Network (2010-2013) (2014) Regional Environmental Inspectorate in Katowice http://stacje.katowice. pios.gov.pl/monitoring/. Accessed 08 Jan 2014

Schädlich G, Weissflog L, Schüürmann G (1995) Magnetic susceptibility in conifer needles as indicator of fly ash deposition. Fresen Environ Bull 4:7-12

Schibler L, Boyko T, Ferdyn M, Gajda B, Holl S, Jordanova N, Rösler W, MAGPROX Team (2002) Topsoil magnetic susceptibility mapping: data reproducibility and compatibility, measurement strategy Stud. Geophys Geod 46:43-57

Schmidt A, Yarnold R, Hill M, Ashmore M (2005) Magnetic susceptibility as proxy for heavy metal pollution: a site study. J Geochem Explor 85:109-117

Spiteri C, Kalinski V, Rösler W, Hoffmann V, Appel E, Team MAGPROX (2005) Magnetic screening of a pollution hotspot in the Lausitz area, Eastern Germany: correlation analysis between magnetic proxies and heavy metal contamination in soils. Environ Geol 49:1-9

Strzyszcz Z, Magiera T (1998) Magnetic susceptibility and heavy metals contamination in soils of southern Poland. Phys Chem Earth (A) 23:1127-1131
Strzyszcz Z, Magiera T, Rachwał M (2006) Application of soil magnetometry for identification of technogenic anomalies of trace metals and iron contents: a case study in the Katowice Forest District. Pol J Environ Stud 15:176-184

Thompson R, Oldfield F (1986) Environmental magnetism. George Allen and Unwin, London, pp 1-227

Urbat M, Lehndorff E, Schwark L (2004) Biomonitoring of air quality in the Cologne conurbation using pine needles as a passive sampler part I: magnetic properties. Atmos Environ 38:3781-3792

Veneva L, Hoffmann V, Jordanova D, Jordanova N, Fehr T (2004) Rock magnetic, mineralogical and microstructural characterization of fly ashes from Bulgarian power plants and the nearby anthropogenic soils. Phys Chem Earth (A) 29:1011-1023

Zawadzki J, Fabijańczyk P, Magiera T (2007) The influence of forest stand and organic horizon development on soil surface measurement of magnetic susceptibility. Pol J Soil Sci 40:113-124

Zawadzki J, Fabijańczyk P, Magiera T, Strzyszcz Z (2010) Study of litter influence on magnetic susceptibility measurements of Urban forest topsoils using the MS2D sensor. Environ Earth Sci 61:223-230 